\title{
HIV-1 Seroreactivity Measurement
}

National Cancer Institute

\section{Source}

National Cancer Institute. HIV-1 Seroreactivity Measurement. NCI Thesaurus. Code C158217.

The determination of the HIV-1 seroreactivity present in a sample. 